Herz 2019 $44: 673$

https://doi.org/10.1007/s00059-019-04864-4

Online publiziert: 28. Oktober 2019

(c) Springer Medizin Verlag $\mathrm{GmbH}$, ein Teil von Springer Nature 2019

Prof. Dr. med. Werner Rudolph, Gründungsmitglied des Deutschen Herzzentrums München (DHM) und ehemaliger Direktor der Klinik für Herz- und Kreislauferkrankungen im DHM, verstarb im 92. Lebensjahr, am 1. Juni 2019. Er gehörte zu den großen Kardiologen unserer Zeit und prägte sowohl in wissenschaftlicher als auch in klinischer Hinsicht dieses umfangreiche Fachgebiet in besonderem Maße. Werner Rudolph wurde am 9. September 1927 in Bienstädt (Thüringen) geboren und besuchte von 1934 bis 1937 die dortige Grundschule. 1938 kam er auf die Oberschule in Gotha. 1942, mit 15 Jahren, wurde er Luftwaffenhelfer, kam 1944 zur Jagdfliegervorschulung nach Brünn, später nach Berlin. Im Januar 1945, mit 18 Jahren, wurde er in die Wehrmacht übernommen. Am 10.05.1945 geriet er in russische Gefangenschaft, erkrankte dort an einer Lungen-Tbc und wurde im September 1947, mit 20 Jahren, entlassen.

1948 bestand er, von Privatlehrern vorbereitet, als Landesbester das Abitur in Gotha. Da er in der DDR nicht studieren durfte, verließ er im Oktober 1949 die DDR und immatrikulierte sich an der Universität Heidelberg für das Fach Medizin. Er führte seine Studien in München, Düsseldorf und Hamburg fort, bestand 1955 in Heidelberg das medizinische Staatsexamen und promovierte im gleichen Jahr. Seine ersten klinischen Erfahrungen sammelte er in Davos (Eidgenössisches pulmonales Sanatorium), in London (Institute of Cardiology und National Heart Institute) und an der TU München (Organisch-chemisches Institut).

1956 lernte er seine Frau in Davos kennen und heiratete im gleichen Jahr in London. 1957 kam seine Tochter Caroline zur Welt. 1959 wurde er wissen-

Ulrich Klein

München, Deutschland

\title{
Nachruf auf Prof. Dr. med. Werner Rudolph
}

schaftlicher Assistent an der II. Medizinischen Klinik der LMU München (Prof. Bodechtel). 1961 erhielt er die Facharztanerkennung für Innere Medizin, 1963 erfolgten die Habilitation sowie die Ernennung zum Privatdozenten, und 1968 wurde er zum außerplanmäßigen Professor ernannt. Von 1963 bis 1973 war er Oberarzt und Leiter der kardiologischen Abteilung der II. Medizinischen Klinik der LMU und baute sie zu einem der modernsten und leistungsfähigsten Zentren in Deutschland auf.

Damit schuf er die anatomischen Voraussetzungen für die operative Behandlung (Prof. Zenker) von Patienten mit Herzklappenfehlern, mit angeborenen Herzfehlern und mit koronaren Herzerkrankungen. 1973 wurde er zum Direktor der Klinik für Herz- und Kreislauferkrankungen im neu gegründeten DHM ernannt. Durch seine gradlinigsystematische, intellektuelle Denk- und Arbeitsweise und durch seinen und seiner Mitarbeiter unermüdlichen Einsatz entstanden wegweisende Forschungsarbeiten auf dem gesamten Gebiet der Kardiologie, speziell hinsichtlich Myokardstoffwechsel und Myokarddurchblutung, Herzmuskelkontraktilität sowie der von ihm entdeckten Nitratintervalltherapie. Seine Energie im klinischen und wissenschaftlichen Bereich war unerschöpflich. Sie bestimmte sein Leben.

Aus seiner Klinik entstanden 535 Publikationen und 815 Vorträge von ihm und seinen Mitarbeitern. Dazu kamen zahlreiche Fortbildungsveranstaltungen an seiner Klinik einschließlich des wissenschaftlichen Symposiums zum 20 jährigen Bestehen des DHM 1994. Auch Ausrichtungen internationaler Symposien, z. B. mit dem amerikanischen Herz- chirurgen D. Cooley in Athen, fanden große Beachtung.

1976 gründete er gemeinsam mit Prof. Dr. U. Klein und Dr. D. Hall die Zeitschrift Herz, heute im 44. Jahrgang. Werner Rudolph war Mitglied zahlreicher inund ausländischer medizinischer Gesellschaften, u.a. des American College of Cardiology. 1980 erhielt er den Bayerischen Verdienstorden und 1987 das Verdienstkreuz 1. Klasse. 1991 nahm er für den Neubau des DHM, an dessen Planung er mitgewirkt hatte, den ersten Spatenstich vor. Ende September 1995 wurde er emeritiert.

Privat liebte er die Musik, insbesondere Opernmusik. Er sammelte Antiquitäten sowie klassische und moderne Kunst. Deswegen schenkten ihm seine Mitarbeiter zu einem Geburtstag ein Bild von Jim Dine (6-farbig nuancierte Herzen). Nach seiner Emeritierung besuchte er an der LMU, im Seniorenstudium, Vorlesungen unterschiedlichster Themenkreise.

Bis zuletzt nahm er ausführlich am Leben teil. Am 1. Juni 2019 schlief er, nach einem erfüllten Leben, im Beisein seiner Tochter friedlich ein.

Prof. Dr. U. Klein, ehemaliger Mitbegründer und Mitherausgeber der Zeitschrift Herz

\section{Korrespondenzadresse}

Prof. Dr. Ulrich Klein

München, Deutschland

klein.ulrich@gmx.de 